S6 Table. Odds ratio $(95 \% \mathrm{Cl})$ of factors associated with abnormal ACR ( $\geq 30 \mathrm{mg} / \mathrm{g})$ in CLHLS and NHANES.

\begin{tabular}{|c|c|c|c|c|c|c|c|}
\hline \multirow{2}{*}{ Characteristics } & \multicolumn{3}{|c|}{ NHANES } & \multicolumn{4}{|c|}{ CLHLS } \\
\hline & n (\%) & OR $(95 \% \mathrm{Cl})$ * & $P$ value & Characteristics & n (\%) & OR $(95 \% \mathrm{Cl})$ * & $\begin{array}{c}P \\
\text { value }\end{array}$ \\
\hline Total & $2177(100)$ & & & Total & $2019(100)$ & & \\
\hline Age group & & & & Age group & & & \\
\hline $65-69$ & $682(31.3)$ & Ref & 1 & $65-69$ & $240(11.9)$ & Ref & 1 \\
\hline $70-74$ & $567(26.1)$ & $1.22(0.90,1.67)$ & 0.200 & $70-74$ & $240(11.9)$ & $0.57(0.30,1.05)$ & 0.076 \\
\hline $75-79$ & $361(16.6)$ & $1.67(1.19,2.33)$ & 0.003 & $75-79$ & $217(10.7)$ & $0.98(0.55,1.75)$ & 0.950 \\
\hline $80+$ & $567(26.1)$ & $2.56(1.86,3.53)$ & $<0.001$ & $80+$ & $1322(65.5)$ & $1.45(0.92,2.37)$ & 0.122 \\
\hline Gender & & & & Gender & & & \\
\hline Male & $1072(49.2)$ & Ref & 1 & Male & $933(46.2)$ & Ref & 1 \\
\hline Female & $1105(50.8)$ & $0.80(0.63,1.02)$ & 0.074 & Female & $1086(53.8)$ & $1.51(1.12,2.06)$ & 0.008 \\
\hline Race/Ethnicity & & & & Race & & & \\
\hline $\begin{array}{l}\text { Mexican } \\
\text { American }\end{array}$ & $169(7.8)$ & Ref & 1 & Han Chinese & $1817(90.0)$ & Ref & 1 \\
\hline Other Hispanics & $188(8.6)$ & $0.90(0.54,1.51)$ & 0.683 & Ethnic minorities & $152(7.5)$ & $0.86(0.53,1.34)$ & 0.509 \\
\hline $\begin{array}{l}\text { Non-Hispanic } \\
\text { White }\end{array}$ & $1151(52.9)$ & $0.86(0.56,1.33)$ & 0.494 & Missing & $50(2.5)$ & $1.11(0.54,2.16)$ & 0.762 \\
\hline $\begin{array}{l}\text { Non-Hispanic } \\
\text { Black }\end{array}$ & $439(20.2)$ & $1.01(0.65,1.58)$ & 0.956 & & & & \\
\hline $\begin{array}{l}\text { Non-Hispanic } \\
\text { Asian }\end{array}$ & $196(9.0)$ & $0.89(0.51,1.53)$ & 0.662 & & & & \\
\hline Other races & $34(1.6)$ & $1.04(0.42,2.54)$ & 0.938 & & & & \\
\hline Education & & & & Education & & & \\
\hline $\begin{array}{l}\text { Below high } \\
\text { school }\end{array}$ & $649(29.8)$ & Ref & 1 & $\begin{array}{l}\text { No formal } \\
\text { education }\end{array}$ & $1238(61.3)$ & Ref & 1 \\
\hline High school & $504(23.2)$ & $1.03(0.76,1.38)$ & 0.864 & Formal education & 764 (37.8) & $0.77(0.56,1.05)$ & 0.102 \\
\hline College or above & $1019(46.8)$ & $0.98(0.73,1.30)$ & 0.862 & Missing & $17(0.8)$ & $1.59(0.52,4.50)$ & 0.392 \\
\hline Missing & $5(0.2)$ & $2.62(0.40,17.29)$ & 0.318 & & & & \\
\hline Income (PIR) & & & & Household income & & & \\
\hline Tertile $1(0-1.87)$ & $928(42.6)$ & Ref & 1 & Tertile $1(<6,000)$ & $637(31.6)$ & Ref & 1 \\
\hline $\begin{array}{l}\text { Tertile } 2 \text { (1.88- } \\
3.86)\end{array}$ & $582(26.7)$ & $0.93(0.71,1.23)$ & 0.618 & $\begin{array}{l}\text { Tertile } 2(6,000- \\
19,000)\end{array}$ & $661(32.7)$ & $1.05(0.79,1.41)$ & 0.73 \\
\hline Tertile $(>=3.87)$ & $474(21.8)$ & $0.90(0.64,1.25)$ & 0.513 & $\begin{array}{l}\text { Tertile } 3(20,000- \\
\text { over } 100,000)\end{array}$ & $572(28.3)$ & $1.50(1.11,2.02)$ & 0.008 \\
\hline Missing & $193(8.9)$ & $0.95(0.65,1.40)$ & 0.803 & Missing & $149(7.4)$ & $1.18(0.71,1.93)$ & 0.51 \\
\hline Marital Status & & & & Marital Status & & & \\
\hline Married & $1173(53.9)$ & Ref & 1 & Married & $774(38.3)$ & Ref & 1 \\
\hline Not married & $1003(46.1)$ & $1.09(0.86,1.37)$ & 0.497 & Not married & $1196(59.2)$ & $1.16(0.86,1.59)$ & 0.338 \\
\hline Missing & $1(0.1)$ & NA & 0.983 & Missing & $49(2.4)$ & $0.98(0.20,4.14)$ & 0.973 \\
\hline Health condition & & & & Health condition & & & \\
\hline Excellent & $158(7.3)$ & Ref & 1 & Very good & $103(5.1)$ & Ref & 1 \\
\hline Very good & $515(23.7)$ & $0.90(0.53,1.52)$ & 0.696 & Good & $750(37.1)$ & $1.18(0.65,2.24)$ & 0.606 \\
\hline Good & $811(37.3)$ & $1.24(0.76,2.04)$ & 0.396 & Fair & $775(38.4)$ & $1.59(0.89,3.02)$ & 0.133 \\
\hline Fair/Poor & $604(27.7)$ & $2.06(1.24,3.42)$ & 0.006 & Bad/Very bad & $213(10.6)$ & $1.30(0.67,2.63)$ & 0.444 \\
\hline Missing & $89(4.1)$ & $3.62(1.06,12.40)$ & 0.040 & Missing & $178(8.8)$ & $1.46(0.73,3.02)$ & 0.293 \\
\hline Smoking status & & & & Smoking status & & & \\
\hline Never smoker & $1096(50.3)$ & Ref & 1 & Never smoker & $1465(72.6)$ & Ref & 1 \\
\hline Former smoker & $857(39.4)$ & $1.16(0.90,1.49)$ & 0.247 & Former smoker & $164(8.1)$ & $0.94(0.57,1.52)$ & 0.816 \\
\hline Current smoker & $222(10.2)$ & $1.45(0.99,2.14)$ & 0.060 & Current smoker & $334(16.5)$ & $0.96(0.64,1.42)$ & 0.835 \\
\hline Missing & $2(0.1)$ & $1.70(0.06,45.06)$ & 0.750 & Missing & $56(2.8)$ & $2.57(0.82,7.64)$ & 0.093 \\
\hline
\end{tabular}




\section{Drinking status}

$\begin{array}{lccc}\text { Never drinker } & 392(18.0) & \text { Ref } & \backslash \\ \text { Former drinker } & 318(14.6) & 1.17(0.81,1.68) & 0.411 \\ \text { Current drinker } & 1356(62.3) & 0.81(0.59,1.11) & 0.190 \\ \text { Missing } & 111(5.1) & 0.40(0.14,1.16) & 0.092\end{array}$

Physical activity

$\begin{array}{lccc}\text { Yes } & 868(39.9) & \text { Ref } & \backslash \\ \text { No } & 1306(60.0) & 0.91(0.72,1.14) & 0.389 \\ \text { Missing } & 3(0.1) & 2.38(0.19,29.96) & 0.502\end{array}$

\section{Body mass index $\left(\mathrm{kg} / \mathrm{m}^{2}\right)$}

$\begin{array}{lccc}\begin{array}{l}\text { Underweight } \\ (<18.5)\end{array} & 36(1.7) & \text { Ref } & \backslash \\ \begin{array}{l}\text { Normal (18.5- } \\ 24.9)\end{array} & 579(26.6) & 0.64(0.30,1.39) & 0.258 \\ \quad \begin{array}{l}\text { Overweight }(25.0- \\ 29.9)\end{array} & 776(35.7) & 0.59(0.27,1.27) & 0.173 \\ \text { Obese (>=30) } & 746(34.3) & 0.71(0.33,1.54) & 0.385 \\ \text { Missing } & 40(1.8) & 2.23(0.81,6.13) & 0.120\end{array}$

\section{Hypertension}

$\begin{array}{lccc}\text { Yes } & 746(34.3) & \text { Ref } & \backslash \\ \text { No } & 1431(65.7) & \mathbf{0 . 4 9 ( 0 . 3 9 , 0 . 6 1 )} & <0.001\end{array}$

\section{Diabetes}

\begin{tabular}{lccccccc} 
Yes & $526(24.2)$ & Ref & $\backslash$ & Yes & $48(2.4)$ & Ref & $\backslash$ \\
No & $1650(75.8)$ & $\mathbf{0 . 4 0}(\mathbf{0 . 3 2}, \mathbf{0 . 5 1})$ & $<0.001$ & No & $1940(96.1)$ & $0.62(0.31,1.34)$ & 0.201 \\
Missing & $1(0)$ & NA & 0.983 & Missing & $31(1.5)$ & $0.92(0.32,2.68)$ & 0.878 \\
\hline
\end{tabular}

\section{Drinking status}

Never drinker

Former drinker

$1528(75.7)$

Ref

Current drinker

$120(5.9)$

$1.28(0.75,2.12) \quad 0.344$

Missing

$315(15.6)$

$1.03(0.70,1.50) \quad 0.877$

Physical activity

\section{Yes}

No

Missing

Body mass index

$\left(\mathrm{kg} / \mathrm{m}^{2}\right)$

Underweight

$(<18.5)$

$56(2.8) \quad 0.40(0.07,1.73) \quad 0.262$

$311(15.4) \quad$ Ref ।

$1598(79.1) \quad 0.93(0.66,1.31) \quad 0.652$

$110(5.4) \quad 1.13(0.57,2.15) \quad 0.726$

477 (23.6) Ref

$1153(57.1) \quad 0.87(0.66,1.14) \quad 0.294$

Overweight (25.0-

29.9)

$229(11.3) \quad 0.58(0.36,0.93) \quad 0.025$

$58(2.9) \quad 0.98(0.47,1.90) \quad 0.948$

$102(5.1) \quad 0.86(0.51,1.43) \quad 0.565$

Missing

$1142(56.6)$

857 (42.4)

Ref

Yes

No

$0.56(0.44,0.72)<0.001$

$20(1.0)$

$0.77(0.21,2.29) \quad 0.664$

\section{Missing}

Diabetes

Diabetes

on models.
Normal (18.5-24.9) 